\title{
EFFECT OF CRYOGENIC FREEZING ON THE TEXTURAL AND SENSORIC PROPERTIES OF DONUTS
}

\author{
KARINA ILONA HIDAS ${ }^{1}$, AdRIENN TÓTH ${ }^{1}$, ESZTER HAMAR ${ }^{1}$, IVETT JAKAB ${ }^{2}$, LÁSZLÓ \\ FRIEDRICH $^{1}$, CSABA NÉMETH $^{3}$ \\ ${ }^{1}$ Szent István University \\ Department of Refrigeration and Livestock Products Technology \\ Budapest 1118 Ménesi St. 43-45. \\ ${ }^{2}$ Szent István University \\ Department of Grain and Industrial Plant Processing \\ Budapest 1116 Villányi St. 29-43. \\ ${ }^{3}$ Capriovus Ltd. \\ Szigetcsép 2317 Dunasor 073/72. \\ Hidas.Karina.Ilona@phd.uni-szie.hu
}

\begin{abstract}
Cryogenic freezing is a mild freezing technology due to the formation of small ice crystals. This preservation technology is well applicable for increasing the shelf life of bakery products. In our experiment, we made donut samples of matured dough, traditional dough with pork fat, and dough with increased fibre content made by adding flaxseed flour. They were fried in palm oil and also in high oleic sunflower oil. Donuts were frozen in liquid nitrogen for 60 seconds and they underwent a storage of 7 days at $-18^{\circ} \mathrm{C}$. Thawing at room temperature and thawing in oven were tested. We investigated how freezing, frozen storage and different thawing processes affect sample texture by penetration. The effect of freezing on water activity and sensory properties were also investigated. In our experiment we found that cryogenic freezing influenced the texture of prepared donuts, but sensory evaluation have shown that this does not lead to a decrease in popularity. In addition, a slight decrease in water activity was observed after freezing and thawing. Heating in oven proved to be the better method for the thawing process of donuts based on sensory properties of products. In addition, consumers preferred the increased fibre content of doughs.
\end{abstract}

Keywords: cryogenic freezing, donut, texture analysis, sensory analysis

\section{INTRODUCTION}

Baking is an ancient, traditional process. Bakery products are the simplest plain pastries, which contain just few ingredients, but they are cakes of numerous components, as well. The term baking is applied for the production of bread, but also for all food products in which the basic material is flour. These products are radiated by heat from the walls and/or top and bottom of a heating equipment (HUI ET AL., 2006). However, donuts are actually fried products, but they inner core is more alike baked products. They absorb substantial amounts of oil during frying (SHIH ET AL., 2001).

Flaxseed nutrition research has increased the potential to be considered as a new ingredient in bakery products (CHETANA ET AL., 2010). Interest in flaxseed consumption is associated with high levels of $\alpha$-linolenic acid, dietary fibre mucilage, lignans and phenolic compounds, all of which are likely to be useful in reducing coronary artery disease, and risk factors for cancer (HOLMAN ET AL., 1982; CUNNANE ET AL., 1993). CHETANA ET AL. (2010) made muffins containing different amounts of flaxseed flour. They concluded that flaxseed increased the water absorption of the flour, like other fibre sources. SHIH and DAIGLE (1999) reported that long-grain rice flour absorpted less oil than wheat flour during frying. 
Nowadays, food preservation technologies are very important to increase shelf life and maintain the nutritional value, texture and flavour of food products (KAALE ET AL., 2011). At temperatures of frozen storage $\left(-18^{\circ} \mathrm{C}\right.$ to $\left.-40^{\circ} \mathrm{C}\right)$ microbiological activity is reduced (GALLART-JORNET ET AL., 2007).

The term cryogenic is applied generally below the temperature of $-150^{\circ} \mathrm{C}$. In contrast, liquid nitrogen $\left(-196^{\circ} \mathrm{C}\right)$ or carbon dioxide $\left(-78^{\circ} \mathrm{C}\right.$ as a solid) are applied directly to food products as freezing medium. Shorter freezing times can be achieved with this process. There is a big temperature difference between the cryogen and the product surface. The high rate of surface heat transfer resulting from the boiling of the cryogen (ZHOU ET AL., 2010).

The goal of our experiment is to investigate the impact of cryogenic freezing on texture, water activity, and sensory properties of donuts made of different doughs, and fried in different media.

\section{MATERIAL AND METHOD}

\section{Donut samples}

In our experiments we made donuts based on different recipes and frying methods. A total of 6 products have been tested. These are shown in Table 1.

Table 1. Tested donut samples

\begin{tabular}{|c|c|c|}
\hline Dough & Frying medium & Sample code \\
\hline \multirow{2}{*}{ Matured dough } & palm oil & K12 \\
\hline & high oleic sunflower oil (HOSO) & K12-HN \\
\hline \multirow{2}{*}{ Traditional dough with pork fat } & palm oil & W7 \\
\hline & high oleic sunflower oil (HOSO) & W7-HN \\
\hline \multirow{2}{*}{$\begin{array}{l}\text { Dough with increased fibre content } \\
\text { (by } 10 \% \text { flaxseed) }\end{array}$} & palm oil & $\mathrm{K}-\mathrm{A}$ \\
\hline & high oleic sunflower oil (HOSO) & K-A-HN \\
\hline
\end{tabular}

\section{Freezing and frozen storage of samples}

After cooling, donuts were frozen by immersion in liquid nitrogen. 15-15 donuts from each types mentioned before were immersed in liquid nitrogen (Messer Hungarogáz Ltd., Hungary). Liquid nitrogen began to boil with a temperature of $-195,8^{\circ} \mathrm{C}$ due to the high temperature difference between the liquid nitrogen and the products. Samples were removed after 60 seconds from the liquid nitrogen by using a stainless strainer. They were then packed into polyethylene bags, sealed with a foil welder and stored in a freezer (Zanussi ZFC26400WA, Italy) at $-18^{\circ} \mathrm{C}$. Samples were tested 24 hours (day 1) and one week (day 7) after freezing.

\section{Thawing process}

Two different thawing methods were tested in this experiment. The first method was letting unpacked donuts thaw at room temperature $\left(20^{\circ} \mathrm{C}\right)$. Our second method was to heat donuts in a preheated oven by convection at $200{ }^{\circ} \mathrm{C}$ for 7 minutes.

\section{Measuring of water activity}

The right amount of free water in the food is essential for the microorganisms, so it is essential to study the water activity in the preservation processes. Water activity was measured by Labmaster-aw (Novasina, Switzerland) before freezing and one day after 
freezing. Measurements were made at $25{ }^{\circ} \mathrm{C}$ with three replicates, maintaining the ratio of dough to filling.

\section{Texture analysis}

Texture properties of different donuts were determined by TA-XT Plus (Stable Micro Systems, UK) by penetration. A penetration cylindrical probe $(\mathrm{P} / 5)$ with a length of $5 \mathrm{~cm}$, a diameter of $5 \mathrm{~mm}$ was used. Measuring cylinder was adjusted to the surface of the samples. The measuring program included a motion of $40 \mathrm{~mm}$ downwards by a speed of 2 $\mathrm{mm} / \mathrm{s}$. Measurements were performed on fresh donuts, on day 1 with both of the thawing types and on day 7 in the oven heated samples. In each case, 5 to 5 measurements were taken on each sample and two samples were analysed, so 10 replicates were performed.

\section{Sensory evaluation}

Consumer sensory tests were performed with 12 consumers, where samples were given three-digit numbers. The following aspects had to be evaluated on a scale of 1 to 10 (1 disliked, 10 favoured): dough colour, odour, taste, texture, greasiness, properness of baking, freshness and overall impression.

\section{Statistical analysis}

Data were analysed by IBM Statistics 24 software. Univariate ANOVA was used to decide whether data are different or not. We checked homogeneity of variances by Levene's test $\left(\mathrm{F}_{\max }(\mathrm{F}(23 ; 216)=1.046 ; \mathrm{p}=0.410), \mathrm{W}_{\text {pen }}(\mathrm{F}(23 ; 216)=1.213 ; \mathrm{p}=0.236), \mathrm{A}_{\mathrm{w}}(\mathrm{F}(11 ; 24)=\right.$ 2.499; $\mathrm{p}=0.29)$ and normality of data by Kormogorov-Smirnov and Shapiro-Wilk tests $\left(\mathrm{F}_{\max }(\mathrm{k}(240)=0.049 ; \mathrm{p}=0.2), \mathrm{W}_{\text {pen }}(\mathrm{k}(240)=0.055 ; \mathrm{p}=0.078), \mathrm{A}_{\mathrm{w}}(\mathrm{k}(36)=0.948 ; \mathrm{p}=0.088)\right)$. We used Tukey tests if variances were equal and Games-Howell test if they were not equal to get differing groups.

\section{RESULTS}

In our experiment we found, that the samples thawed at room temperature had unfavourable sensory properties. In addition, their handling is difficult, and due to the long and unregulated thawing process, it is also disadvantageous from an industrial point of view. Therefore, only samples thawed in the oven were examined in the measurement of the water activity. Texture analysis was performed on the samples thawed at room temperature only on day 1.

\section{Changing of water activity}

Figure 1 shows the water activity of examined donut samples before and after cryogenic freezing. We performed univariate ANOVA based on 3 factors. These factors are the following: frying medium, dough material and freezing. The effect of frying medium was not significant $(\mathrm{Aw}$, oil $(\mathrm{F}(11 ; 24)=0.284 ; \mathrm{p}=0.599))$, but the effect of freezing and dough material was significant $\left(\mathrm{A}_{\mathrm{w}}\right.$, dough $(\mathrm{F}(11 ; 24)=10.236 ; \mathrm{p}<0.001), \mathrm{A}_{\mathrm{w}}$, time $(\mathrm{F}(11 ; 24)=11.899$; $\mathrm{p}<0.01)$. Freezing and thawing decreased water activity. This may indicate that during the thawing (baking in oven for 7 minutes at $200^{\circ} \mathrm{C}$ ) a certain amount of water has been lost (evaporated). In addition, dough material had a significant effect on water activity, as well. Water activity of matured dough was significantly higher, than the other samples doughs water activity. 


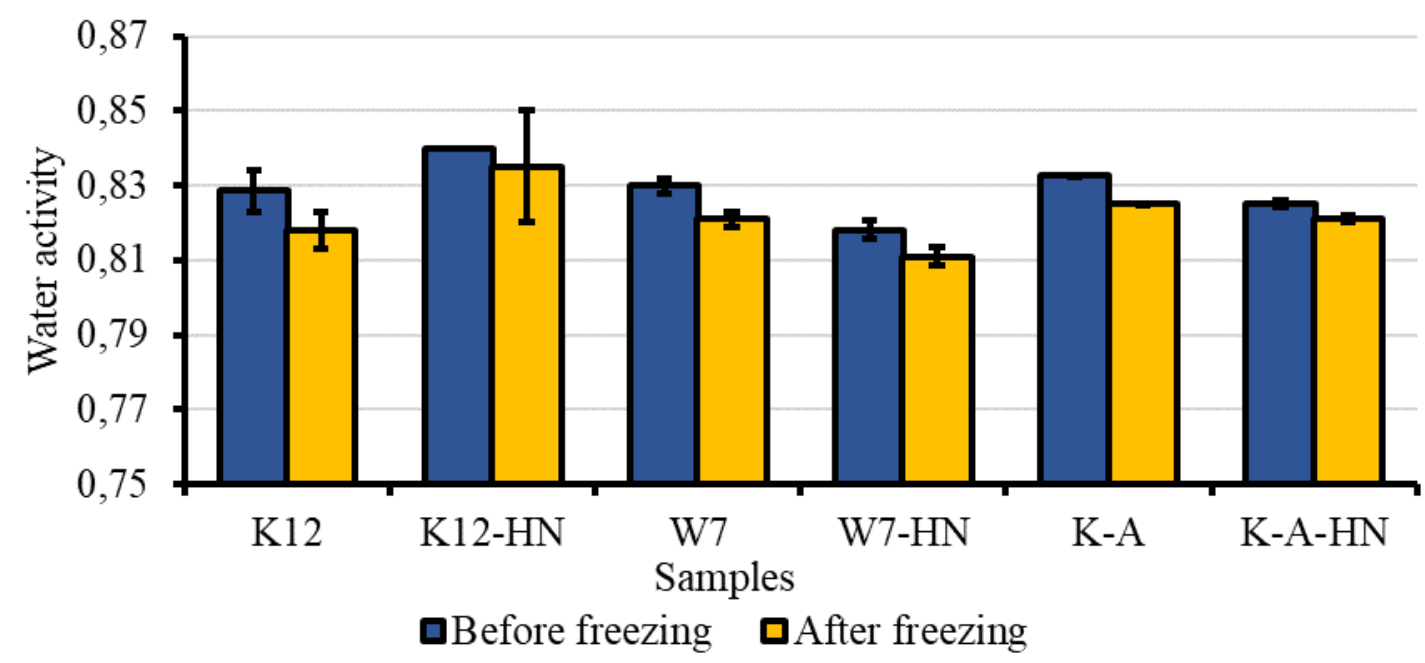

Figure 1. Water activity of donut samples before and after cryogenic freezing

\section{Results of texture analysis}

The results of the maximum penetration force describe the force required to penetrate the probe to draw conclusions on the hardness of the product. Figure 2 shows the maximum force required to penetrate each sample. It can be seen that the standard deviation values are relatively large. The reason for this is primarily due to the structure of the dough. Air bubbles of very different sizes and distributions are present in each sample. In addition, the surface of the donuts is relatively uneven. Different freezing times and different ways of thawing had different effects on different samples, but the statistical analysis revealed that the maximum force required to penetrate the samples tested before freezing was significantly different from the samples tested after freezing $\left(\mathrm{F}_{\max }\right.$, time $(\mathrm{F}(23 ; 216)=15.317$; $\mathrm{p}<0.0001)$. In addition, the baking medium and the material of the dough also had a significant effect on the maximum force $\left(\mathrm{F}_{\max }\right.$, oil $(\mathrm{F}(23 ; 216)=14.656 ; \mathrm{p}<0.0001), \mathrm{F}_{\max }$, dough $(\mathrm{F}(23 ; 216)=31.714 ; \mathrm{p}<0.0001))$.

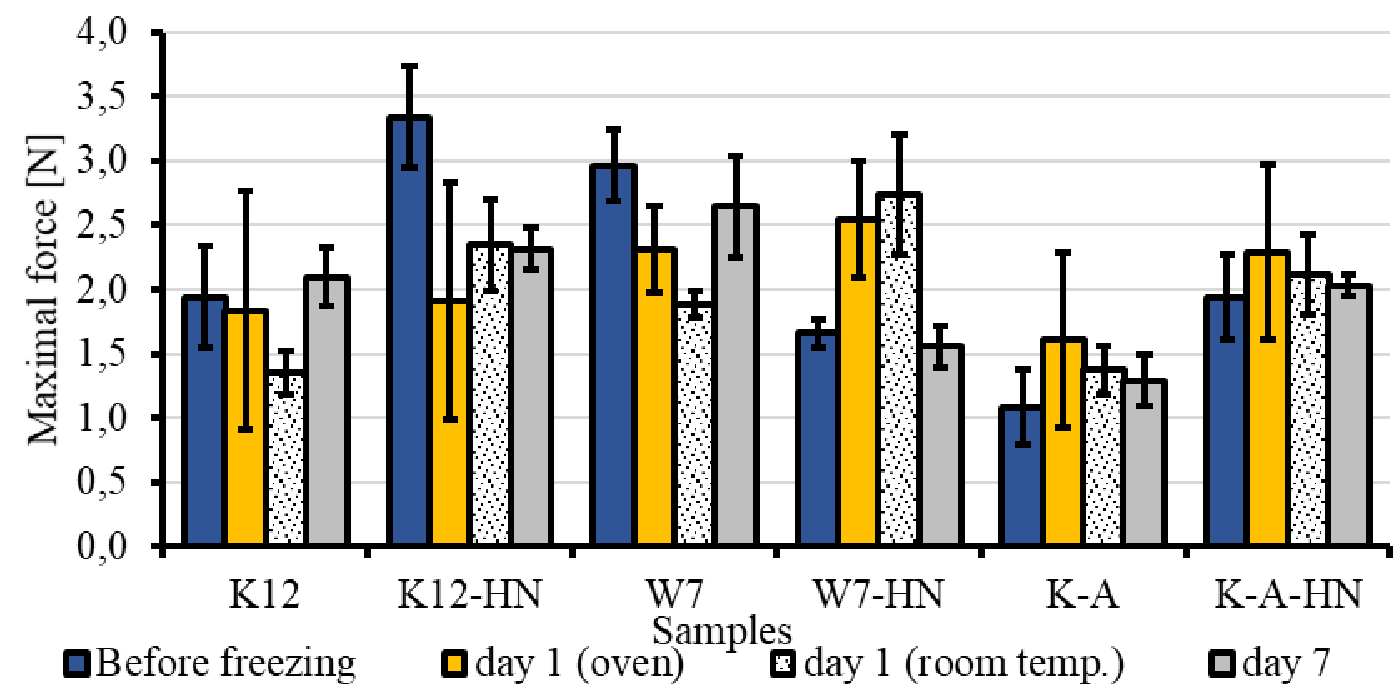

Figure 2. Maximal force of penetration of donuts before freezing, one day after cryogenic freezing thawed in oven for 7 minutes at $200^{\circ} \mathrm{C}$ (day 1 (oven)), and thawed at room temperature (day 1 (room temp.)) and after 7 days of storage at $-18^{\circ} \mathrm{C}$ (day 7 ) 
The value of penetration work (Figure 3) expresses all the work required to penetrate the probe in donut samples. There is no clear trend in the development of penetration work, but it can be said that there is a significant difference $\left(\mathrm{W}_{\text {pen, }}\right.$ time $(\mathrm{F}(23 ; 216)=10.532$; $\mathrm{p}<0.0001)$ ) between the data measured before freezing and the measured data after freezing. In addition, the penetration work done in the traditional dough differs from the other two and the baking medium had also significant effect on the penetration work ( $\mathrm{W}_{\text {pen, }}$ oil $\left.(F(23 ; 216)=113.794 ; p<0.0001), W_{\text {pen, dough }}(F(23 ; 216)=24.605 ; p<0.0001)\right)$.

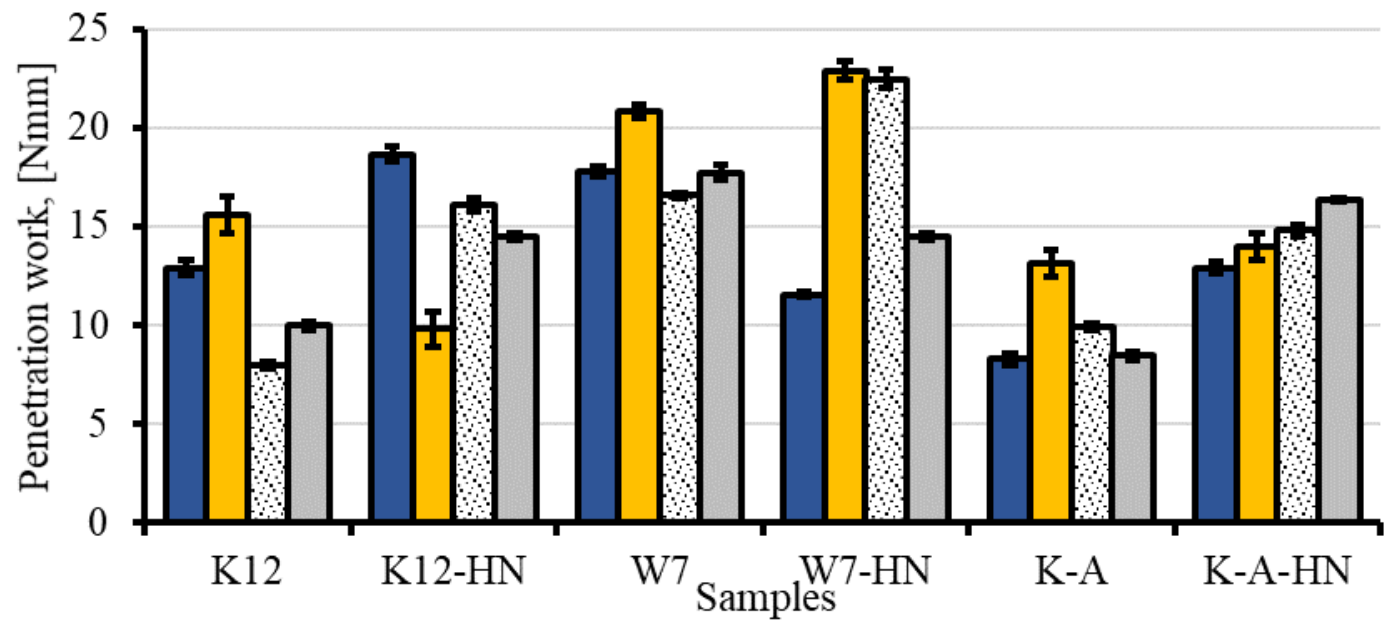

$\boldsymbol{\square}$ Before freezing $\boldsymbol{\square}$ day 1 (oven) $\boldsymbol{\nabla}$ day 1 (room temp.) $\boldsymbol{\square}$ day 7

Figure 4. Penetration work of donut samples before freezing, one day after cryogenic freezing thawed in oven for 7 minutes at $200^{\circ} \mathrm{C}$ (day 1 (oven)), and thawed at room temperature (day 1 (room temp.)) and after 7 days of storage at $-\mathbf{1 8}^{\circ} \mathrm{C}$ (day 7 )

Results of sensory evaluation

Before freezing

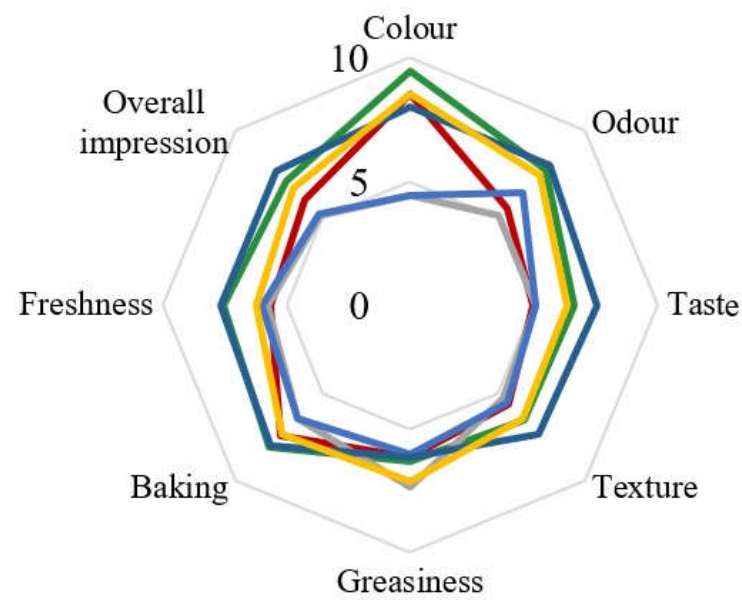

\section{After freezing}

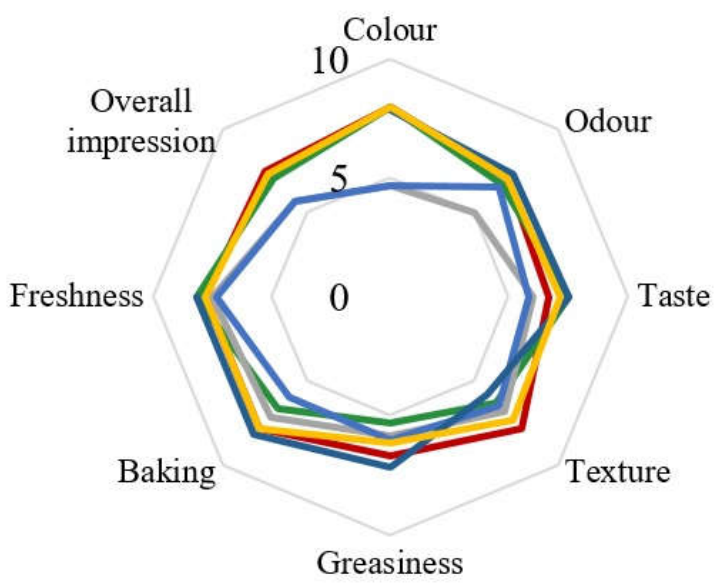

Greasiness

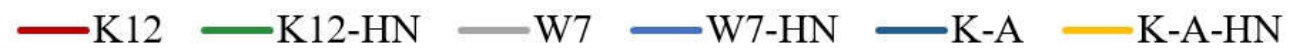

Figure 5. Results of sensory evaluation before freezing and after cryogenic freezing and thawing in oven after 1 day 
Results of the sensory analysis performed with consumers can be seen in figure 5. Sample W7-HN received the lowest score for all aspects before freezing. In contrast, the K12-HN and K-A samples showed good organoleptic properties. In contrast, on the first day after freezing, samples received much better score values. The reason for this is probably due to the fact that the donuts were released in a hot oven at $200{ }^{\circ} \mathrm{C}$ for 7 minutes before the judgment. Thawing in oven influenced positively the surface structure of the product, the samples received a fresh, crunchy texture, and a relatively large amount of fat and oil was poured out of the donut pastries, so the fatty feeling decreased for the donuts.

\section{CONCLUSIONS}

We found that freezing in liquid nitrogen changed the texture properties of donut samples. However, it did not cause the decrease of popularity of products based on the consumer sensory evaluation. The results show that freezing decreased water activity of products. Further microbiological and sensory tests are needed to determine the shelf life of there products.

\section{ACKNOWLEDGEMENTS}

Our research is sponsored by the project „Egg white based dairy product analogs with probiotic effects for allergic people and development of low-fat and carbohydrate products for people on a protein-dense diet VÁLLALATI KFI_16"”.' We are very thankful for that.

\section{REFERENCES}

Hui, Y. H., CoRke, H., De LeYn, I., NiP, W. K., Swanson, R. B. (2006): Bakery products: science and technology. Blackwell Publishing, Iowa.

Sudha, M. L., BEGUM, K., RAmasarma, P. R. (2010): Nutritional characteristics of linseed/flaxseed (Linum usitatissimum) and its application in muffin making. Journal of Texture Studies 41: 563-578.

Cunnane, S. C., Ganguli, S., Menard, C., Liede, A. C., Hamadeh, M. J., Chen, Z. Y., JENKINS, D. J. (1993): High $\alpha$-linolenic acid flaxseed (Linum usitatissimum): some nutritional properties in humans. British Journal of Nutrition 69: 443-453.

Holman, R. T., Johnson, S. B., HATch, T. F. (1982): A case of human linolenic acid deficiency involving neurological abnormalities. The American Journal of Clinical Nutrition 35: 617-623.

Shih, F. F., Daigle, K. W., Clawson, E. L. (2001): Development of low oil $\square$ uptake donuts. Journal of Food Science 66: 141-144.

ShiH, F. F., DAigle, K. W. (1999): Oil uptake properties of fried batters from rice flour. Journal of Agricultural and Food Chemistry 47: 1611-1615.

KaAle, L. D., EikeViK, T. M., Rustad, T., Kolsaker, K. (2011): Superchilling of food: A review. Journal of ood Engineering 107: 141-146.

Gallart-Jornet, L., Rustad, T., BARAt, J. M., Fito, P., Escriche, I. (2007): Effect of superchilled storage on the freshness and salting behaviour of Atlantic salmon (Salmo salar) fillets. Food Chemistry 103: 1268-1281.

ZhOU, G. H., XU, X. L., LIU, Y. (2010): Preservation technologies for fresh meat-A review. Meat Science 86: 119-128. 